either a trophic influence passing from the cerebral centres of the right hemisphere to the musculature of the body on the same side, or the extension of a secondary degeneration of the direct and crossed pyramidal tracts into the gray substance of both anterior horns. Perhaps the atrophy from disuse may help to explain why the small muscles of the hand are so frequently affected.

\title{
GLOSSO-LABIAL-I,ARYNGEAL I'ARALYSIS.
}

In the Gaz. des hopitaux, 1889, No. 141, Moty reports the history of three cases of bulbar paralysis whose etiology is deserving of attention and consideration. All of those affected were members of one and the same family, whose parents were first cousins on the paternal side. The parents were in good health. Among others of the family several marriages of blood-relations had taken place, without any apparent ill effect upon their progeny. In the above-mentioned family there were eleven children. The eldest was twenty-seven years of age, in good health, married, and the mother of two living children. The second child, also a daughter, twenty-five years of age, was healthy until her eightl year, when the symptoms of bulbar paralysis began.

In the third daughter, twenty-three years old, the disease began to develop itself at the seventh year. The fourth child, a son of twenty-seven years, was healthy at birth, but through a fall in his first year he received a dislocation of the right thigh. The first signs of the disease appeared likewise in the seventh year. The fifth child is a son nineteen years of age. Three years ago he acquired a tuberculous ostitis in one of the thighs. The sixth, seventh, eighth and ninth children were boys. The tenth and eleventh were girls. The last one was born five years ago. The author, who doubts the legitimacy of the first child, calls attention to the fact that the disease affected the eldest three legitimate children, and according to the general laws of heredity, the first children suffered most from hereditary influences. Besides the relationship of the parents, there was also the pernicious influence of alcoholic excesses.

RELIEF FROM A GRAVE TVPE OF EPILEPSY FOI,LOWIN(; THE CORRECTION OF AN EXAGGERATED CONVERGENT STRABISMUS.

Dr. Chas. H. Beard (Archives of Ophthalmology, Apr. and July, I 890), reports the case of a German barber fiftytwo years of age, who suffered from excruciating pain in 
the left eye, affecting the distribution of the fifth nerve on the same side. This pain, which began in the eye, had been first felt eight or ten years previous, and had become almost constant. At about the same time the left eye deviated inwards, the pain and the convergence gradually increasing. until the one had become unbearable, and the other had progressed to the extreme limit. It was only by a decided effort at abduction that a portion of the cornea could be brought into view. Four or five years previous he began to have epileptic attacks, which increased in frequency and severity until he had as many as three or four fits within twenty-four hours.

The mental faculties were not affected, in fact the man was intellectually much above the average of his class. There was also in this case total deafness, evidently due to disease of the labyrinth which had begun twenty-five years before. Otherwise he enjoyed excellent health.

The morbid eye had grown amblyopic, the retina retaining its function but feebly on the nasal side only. In all respects not mentioned, the eye was normal. Vision in the fellow eye was good, and there was no error in the refraction of either eye.

The operation of advancement of the left external rectus combined with a thorough tenotomy of the left internus, was done under ether. Recovery was prompt, and the result most gratifying; for not only was there correction of the deformity, but from that time till the patient's death, which occurred from a railway accident on the $22 \mathrm{~d}$ day of June, 1889. fully fifteen months later, he neither suffered from the old agonizing pain, nor had a single fit of epilepsy.

\section{THOMSEN'S DISEASE: (Myotonia Congenita).}

Erb (Deutsch. Archiv. für Klin. Med. Bd. XIV., Hft. 5 u 6), briefly relates the history of the cases of Thomsen's disease published since his first contribution in 1886 .

There were seven cases in all. While other observers have confirmed in almost every detail the symptoms described by E., it is remarkable that none of these could discover the rythmical wave-like contractions manifested under the stabile influence of the galvanic current.

As these peculiar contractions were demonstrable in his five recent cases, he consideres them as a constant, and therefore probably pathognomunic symptom. The fact that others have not succeeded in evoking this symptom he believes must be accounted for by the circumstance that on the one hand it has not been searclied for with the nec- 